\title{
FLOOD FREQUENCY ANALYSIS AND IMPACT ASSESSMENT FOR CLIMATE CHANGE IN THE NAGARA RIVER BASIN
}

\author{
Morihiro HARADA ${ }^{1}$, Yasuyuki MARUYA ${ }^{2}$, Toshiharu KOJIMA ${ }^{3}$, Daisuke \\ MATSUOKA $^{4}$, Yujin NAKAGAWA ${ }^{5}$, Shintaro KAWAHARA 6 and Fumiaki ARAKI ${ }^{7}$ \\ ${ }^{1}$ Member of JSCE, Associate Professor, River Basin Research Center, Gifu University \\ (1-1 Yanagido, Gifu-city, Gifu 501-1193, Japan) \\ E-mail:m-harada@green.gifu-u.ac.jp \\ ${ }^{2}$ Member of JSCE, Research Associate, River Basin Research Center, Gifu University (ditto) \\ E-mail: maruya@green.gifu-u.ac.jp \\ ${ }^{3}$ Member of JSCE, Associate Professor, River Basin Research Center, Gifu University (ditto) \\ E-mail:kojima@green.gifu-u.ac.jp \\ ${ }^{4}$ Non-member, Japan Agency for Marine-Earth Science and Technology (3173-25 Showa-machi, Kanazawa-ku, \\ Yokohama-city, Kanagawa 236-0001, Japan) \\ E-mail: daisuke@jamstec.go.jp \\ ${ }^{5}$ Non-member, Japan Agency for Marine-Earth Science and Technology (ditto) \\ E-mail: nakagawa.yujin@jamstec.go.jp \\ ${ }^{6}$ Non-member, Japan Agency for Marine-Earth Science and Technology (ditto) \\ E-mail: kawahara@jamstec.go.jp \\ ${ }^{7}$ Non-member, Japan Agency for Marine-Earth Science and Technology (ditto) \\ E-mail: arakif@jamstec.go.jp
}

\begin{abstract}
This research proposes a procedure to conduct climate change impact assessment on flood risks aimed at having smooth risk communication with river managers and citizens. The large ensemble database "d4PDF" was applied to flood runoff analysis model used to develop the flood prevention plan by the river manager. This method expresses the climate change impact in expressions that are easy for river managers to understand by applying the climate model product into the flood runoff model used in the official flood prevention planning. The proposed method was verified in the Nagara River basin, which has a basin population of about 830,000 in mainly the downstream area and no large dam in the upstream of main stream. The hydrological observation data were utilized for verification of the flood runoff model calculation results. The results of the flood runoff analysis by the annual maximum rainfall event extracted from d4PDF NHRCM 20 well represented the distribution of annual maximum flood observations. Although the influence of the spatial resolution of the climate model is still unclear, the assessment procedure presented by this research has versatility applicable to other river basins.
\end{abstract}

Key Words : climate change, adaptation, flood risk, $d 4 P D F$, runoff analysis

\section{INTRODUCTION}

The increase in extreme weather events associated with climate change, combined with changes in social condition, is recognized as a strong risk factor for the sustainable development of nations and regions. The momentum for predicting the impacts of climate change on flood risks and discussing adaptation measures has never been greater. In the field of water disaster prevention in Japan, the Ministry of Land, Infrastructure, Transport and Tourism (MLIT) has been developing expected flood inundation area maps based on the assumed maxi- mum external force and a vision for rebuilding the society for water disaster prevention awareness, following the occurrence of record heavy rain and disaster damage in recent years.

On the other hand, there are several issues to connect climate change prediction information and impact assessment information to the study of adaptation measures and their social implementation. One of the issues is the uncertainty of climate predictions. Uncertainty in climate predictions arises from three distinct sources: the natural fluctuations, model uncertainty, and scenario uncertainty. It has been shown that the proportion of these uncertain- 
ties varies depending on the forecast lead time and region ${ }^{1)}$. It has been pointed out that predictions by climate models may underestimate extreme weather events, because models seem to underestimate the observed increase in heavy precipitation with global warming ${ }^{2}$. As one response to these uncertainties, a large-scale ensemble calculation of multiple models for the global and the region around Japan has been carried out ${ }^{3), 4)}$, and the database ${ }^{5)}$ has been released. Many research results of flood risk assessment using these databases are also being reported.

However, there are still many institutional and engineering issues if we are to expand flood risk assessment into adaptation measures with effectiveness. It is difficult to implement climate change prediction information into the river management plan because the present laws and technical standards related to river management do not have a mechanism that takes into account future increases in external forces. Furthermore, the gap between the practical planning theory and methods used in river management practices and the impact assessment theory and methods proposed by recent studies, may make it difficult for the river manager to understand and use the impact assessment results.

This study proposes a climate change impact assessment method for river flood frequency that enables smooth risk communication with river managers and citizens. This method verifies the climate model product using the runoff analysis model and hydrological observation data used by river managers for planning. Furthermore, the impact of climate change on flood discharge is evaluated using a climate model product. The flood return period is evaluated by taking advantage of a large ensemble number of the climate model product, $\mathrm{d} 4 \mathrm{PDF}^{4}$. These evaluation results are presented in easy-tounderstand expressions for river managers. This method was applied to the Nagara River basin located in central Japan. We also examined the versatility and applicability of this method.

\section{METHODS}

\section{(1) Methods outline and procedure}

The Nagara River basin, which has a basin population of about 830,000 in mainly the downstream area and no large dam in the upstream of main stream, was selected as the test site of this method because this basin is considered to be more directly affected by climate change impact. Fig.1 shows the location of the river basin. In this basin, hydrological observations are conducted by the river managers and the Japan Meteorological Agency.
Fig.2 shows the procedure of this study. After [1] building a flood runoff model for the Nagara River basin, [2] the reproducibility of the flood peak discharge is confirmed by reproducing the past major floods. These procedures are equivalent to reproducing the methods used by river managers for official river management planning. Afterwards, [3] Annual Maximum Precipitation (AMP) events are extracted from d4PDF, and [4] extracted AMP events are analyzed with the flood runoff model, to obtain peak flood discharge corresponding to each AMP events. [5] The calculated peak flood discharges with the AMP events from historical climate simulations are bias-corrected using the observed annual peak flood discharge values, and [6] possible flood discharge is calculated from the biascorrected cumulative distributions of calculated peak flood discharges.

We employed the d4PDF ${ }^{4}$ (database for Policy Decision making for Future climate change) as the climate change prediction information for the flood frequency analysis. We extracted the hourly precipitation dataset from d4PDF NHRCM (horizontal resolution: $20 \mathrm{~km}$ ), historical climate simulation and $+4 \mathrm{~K}$ future climate simulation. In general river flood prevention planning, a limited number of annual extreme values such as precipitation and peak flood discharge are used for hydrological statistical theory for extreme values. On the contrary, d4PDF has a large ensemble number and the total number of experiment years reaches thousands of years. It is considered to have advantages, such as the inclusion of extreme meteorological phenomena with low occurrence frequency, and the occurrence frequency can be evaluated using non-parametric frequency distribution of annual extreme values. While the historical climate simulation is based on observations, such as sea surface temperature (SST)

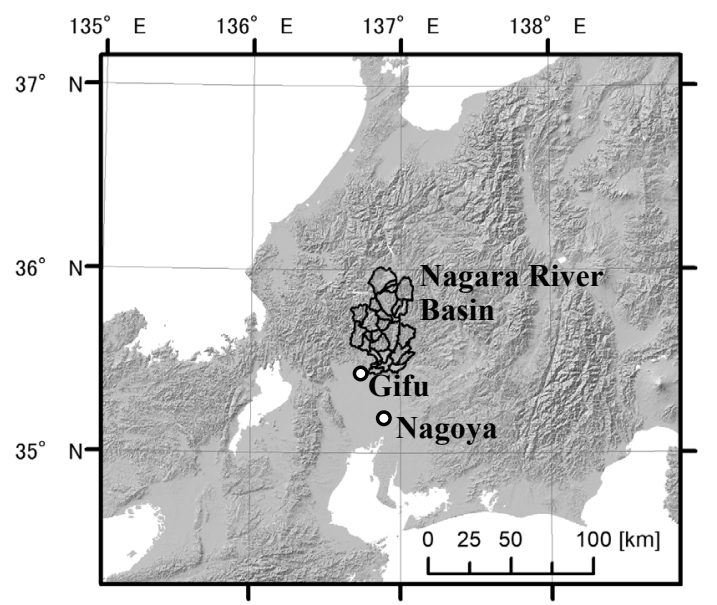

Fig.1 Location of the Nagara River basin. The basin population is about 830,000 in mainly the downstream area and no large dam in the upstream of main stream. 
[1] Flood runoff modeling of the Nagara River ba-

[2] Model verification by calculation of past major floods with observation data sets $(n=13)$

[3] Extraction of Annual Maximum Precipitation (AMP) events from d4PDF (historical climate, $+4 \mathrm{~K}$ future climate)

[4] Flood runoff analysis of AMP events (historical climate $\mathrm{n}=3,000,+4 \mathrm{~K}$ future climate $\mathrm{n}=5,490$ )

[5] Bias correction of calculated peak flood discharge with the observed annual peak flood discharge $(n=54)$

[6] Evaluation of T-year possible flood discharge from the bias-corrected cumulative distributions of peak flood discharges (historical climate, $+4 \mathrm{~K}$ future climate)

Fig.2 Procedure diagram of this study.

from 1950 to 2011 , the $+4 \mathrm{~K}$ future climate simulation assumed a $4 \mathrm{~K}$ increase compared to before the Industrial Revolution (around 2090 in the RCP8.5 scenario) and six SST patterns are given. By applying the results of these two numerical experiments to flood frequency analysis, we compared the flood frequency distribution from the past to the present and the future when the global warming progresses. In the $+4 \mathrm{~K}$ future climate experiment, it has been reported that the trend of precipitation extremes varies depending on the SST pattern ${ }^{6}$. In this study, all ensembles were used together to propose a simple method.

\section{(2) Flood runoff modeling and verification}

The model used for flood runoff analysis was the storage function method. The calculation was performed by a Fortran program. The Nagara River basin with a basin area of about $1,700 \mathrm{~km}^{2}$ was divided into 27 small watershed models. These small watershed models were connected by 15 river channel models. The parameters for the small watershed models and river channel models were adjusted by the calculation of past major floods with observation data sets. These model settings and parameters reproduced the model used by the river manager.

Fig.3 shows the schematic image of the storage function model of the Nagara River Basin. The model parameters for the small basin model are:

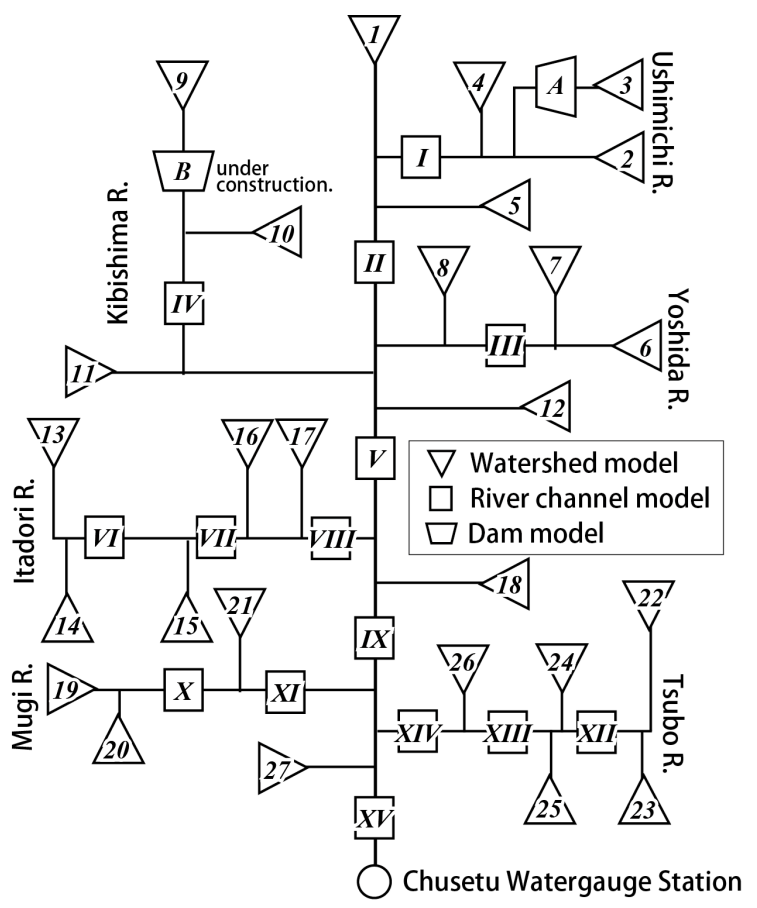

Fig.3 Schematic image of storage function model of the Nagara River basin (27 watershed models and 15 river channel models).

basin areas $A$, storage constants $K$ and $P$, delay time $T$. The river channel model also needs $K, P$, and $T_{l}$. The initial values of these model parameters were set to the values used when river managers considered river improvement plans.

The reproducibility of peak flood discharge was examined for 13 flood events. These events were extracted from the major flood records that occurred in the past, which obtained the observed values of peak flood discharge at the flow gauging station and the rainfall hyetograph that caused the flood. The precipitation hyetographs at rain gauge stations were processed into the 27 hyetographs for small watershed models by using the Thiessen method.

\section{(3) Extracting the AMP events from d4PDF}

AMP events in the Nagara River basin were extracted from the d4PDF NHRCM. There were 3,000 AMP events from historical climate experiments (September 1950 to August 2011, 50 members), 5,490 events from $+4 \mathrm{~K}$ future climate experiments (September 2050 to August 2111, 90 members), respectively. The AMP event in the Nagara River basin was determined by 48-hour rainfall in the basin areal-averaged rainfall. First, to calculate the basin areal-averaged precipitation, hourly precipitation time series data of the nine grids covering the Nagara River basin were extracted from the surface meteorological data of each ensemble. The 
area-weighted average value was calculated as the basin areal-averaged rainfall according to the overlap of the nine grids and the Nagara River basin. The hyetograph for the 27 small watershed models, which was the input data for the runoff analysis model, was generated for 17 days ( 8 days before and after the AMP event occurs).

\section{(4) Flood runoff analysis with AMP events}

Flood runoff analysis was conducted for the 3,000 AMP events from historical climate experiments and 5,490 AMP events from $+4 \mathrm{~K}$ future climate experiments. Flood discharge hydrograph and peak flood discharge were calculated at each point in the model. Flood frequency was analyzed at the Chusetsu watergauge station, located at the most downstream point of the model.

\section{(5) Bias-correction and evaluation of possible flood discharge}

The calculated peak flood discharge from flood runoff model from historical climate experiments $(n=3,000)$ were compared with the observed annual peak flood discharge at the Chusetsu watergauge station ( $\mathrm{n}=54$, from 1962 to 2015). The bias of the cumulative frequency distribution of the calculated values from historical climate experiments was confirmed by the observed values, and a simple correction method was tried so that the cumulative frequency distribution of the calculated values matched the observed values. We tested the two simple methods. The both methods assumed that the frequency distribution of peak flood discharge followed the Gumbel distribution. The discharge values were arranged in ascending order from the minimum value to the maximum value, and the cumulative distribution was plotted with the occurrence probability $p_{i}$ of the value as $p_{i}=(i-\alpha) /(\mathrm{n}+1-$ $2 \alpha$ ), here $\alpha=0.44$. The corrected flow rate was set as $Q_{p i}{ }^{\prime}=C Q_{p i}$, and the flow rate $Q_{p i}$ before correction was multiplied by the correction coefficient $C$ to correct the bias.

[Method 1] is a method for obtaining a coefficient $C$ that minimizes the RMSE with the cumulative distribution of the corrected value with respect to the cumulative distribution using the observed values directly. In [Method 2], the Gumbel distribution was obtained from the observed values, and the RMSE with the cumulative distribution of the corrected value was minimized for only the region with a non-excess probability of $90 \%$ or more (return period of 10 years or more). Method 2 is a correction method that focuses only on large-scale floods with low probability of occurrence. The results of these two methods were compared, and the correction factor adopted was also applied to the peak flood discharge frequency distribution $(\mathrm{n}=$ 5,490 ) based on $+4 \mathrm{~K}$ future climate experiment. Using the cumulative distribution frequency of modified peak flood discharges obtained by this method nonparametrically, the T-year possible flood discharge $Q_{T}$ was calculated directly from the cumulative distribution, where $p_{T}=1-(1 / \mathrm{T})$.

\section{RESULTS}

\section{(1) Flood runoff model verification}

Runoff analysis was conducted for 13 major floods in the past. The reproducibility of peak discharge, which is the most important variable in flood frequency analysis, was confirmed. Table 1 shows the dates of occurrence of 13 major floods, peak flood discharges, and calculated flood peak discharges. Fig.4 shows the comparison of observed and calculated values. The analysis result has an error of $38 \%$ at maximum with respect to the observed value, but the error is within $10 \%$ in the top three cases.

Table 1 Observed and calculated peak discharges of major floods at the Chusetsu watergauge station.

\begin{tabular}{|c|c|c|c|}
\hline $\begin{array}{c}\text { Date } \\
(\mathrm{Y} / \mathrm{M} / \mathrm{D})\end{array}$ & $\begin{array}{c}\text { Observation } \\
{\left[\mathrm{m}^{3} / \mathrm{s}\right]}\end{array}$ & $\begin{array}{c}\text { Calculation } \\
{\left[\mathrm{m}^{3} / \mathrm{s}\right]}\end{array}$ & Error \\
\hline $2004 / 10 / 19$ & 7667 & 8195 & 0.07 \\
\hline $1999 / 9 / 14$ & 6026 & 5529 & -0.08 \\
\hline $1990 / 9 / 17$ & 5750 & 5833 & 0.01 \\
\hline $2002 / 7 / 9$ & 5334 & 4616 & -0.13 \\
\hline $1998 / 7 / 27$ & 5169 & 3941 & -0.24 \\
\hline $2006 / 7 / 17$ & 3309 & 3394 & 0.03 \\
\hline $1989 / 9 / 5$ & 3302 & 3701 & 0.12 \\
\hline $1997 / 11 / 25$ & 3281 & 4044 & 0.23 \\
\hline $1985 / 6 / 29$ & 2883 & 3208 & 0.11 \\
\hline $1995 / 7 / 02$ & 2863 & 3434 & 0.20 \\
\hline $1983 / 9 / 27$ & 2666 & 3336 & 0.25 \\
\hline $2009 / 7 / 26$ & 2424 & 2228 & -0.08 \\
\hline $1992 / 8 / 12$ & 1965 & 2706 & 0.38 \\
\hline
\end{tabular}

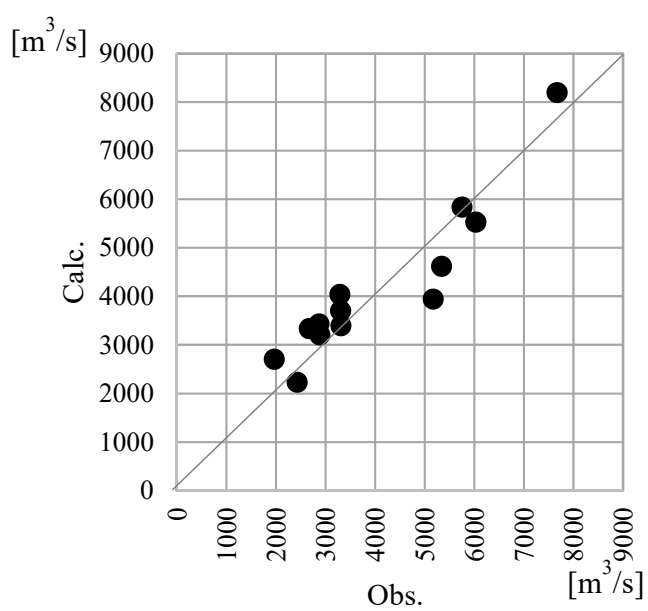

Fig.4 Comparison of observed and calculated values. 
In the simulation of flood by Typhoon 23th in 2004 , which was the largest in the history of observation, the observed peak flood discharge at the Chusetsu watergauge station was about $7,700 \mathrm{~m}^{3} / \mathrm{s}$, whereas the calculation result was about $8,200 \mathrm{~m}^{3} / \mathrm{s}$. In this flood case, a large-scale inundation occurred between the mountainous areas upstream from the Chusetsu, and the peak discharge considering the peak flow reduction caused by the inundation was estimated to be $8,023 \mathrm{~m}^{3} / \mathrm{s}^{7}$. For this reason, the design flood discharge for the Nagara River was set to $8,100 \mathrm{~m}^{3} / \mathrm{s}$ by the river manager. The calculation results of the model in this study were close to this value. Based on the above, it was concluded that this model can calculate the peak discharge of large-magnitude floods in the Nagara River basin with practical accuracy.

\section{(2) The frequency distribution of peak flood dis- charge}

Fig.5 shows the frequency distribution of the observed annual maximum discharge $(\mathrm{n}=54)$ in the Chusetsu watergauge station and the peak flood discharge frequency distribution in the runoff analysis results of the AMP events extracted from d4PDF. The frequency distribution of observations (upper part of Fig.5) is not smooth, but the calculation results using d4PDF in both the historical experiment (middle part of Fig.5) and the $+4 \mathrm{~K}$ experiment (lower part of Fig.5) show smooth distributions similar to the Gumbel distribution that is commonly used to represent extreme value distributions on hydrological statistics. Comparing the results of the historical experiment and the $+4 \mathrm{~K}$ experiment, it was confirmed that the distribution peak has moved slightly to the right and the right side has expanded, although the lower limit of the distribution is almost the same. In other words, it can be seen that the frequency of floods with higher flow rates is increasing.

The frequency distribution obtained from the analysis results using d4PDF can be used as a nonparametric probability density function (PDF) because the number of samples is very large. At the same time, it is considered that the flood discharge corresponding to the non-excess probability can be evaluated directly from the cumulative distribution function (CDF). However, it is necessary to correct the bias that the calculation result has for the observation result.

\section{(3) Bias correction}

The average annual maximum discharge based on the observed value $(\mathrm{n}=54)$ was $3,024 \mathrm{~m}^{3} / \mathrm{s}$, while the average value of the flood frequency distribution using the AMP event $(n=3000)$ of $d 4 P D F$
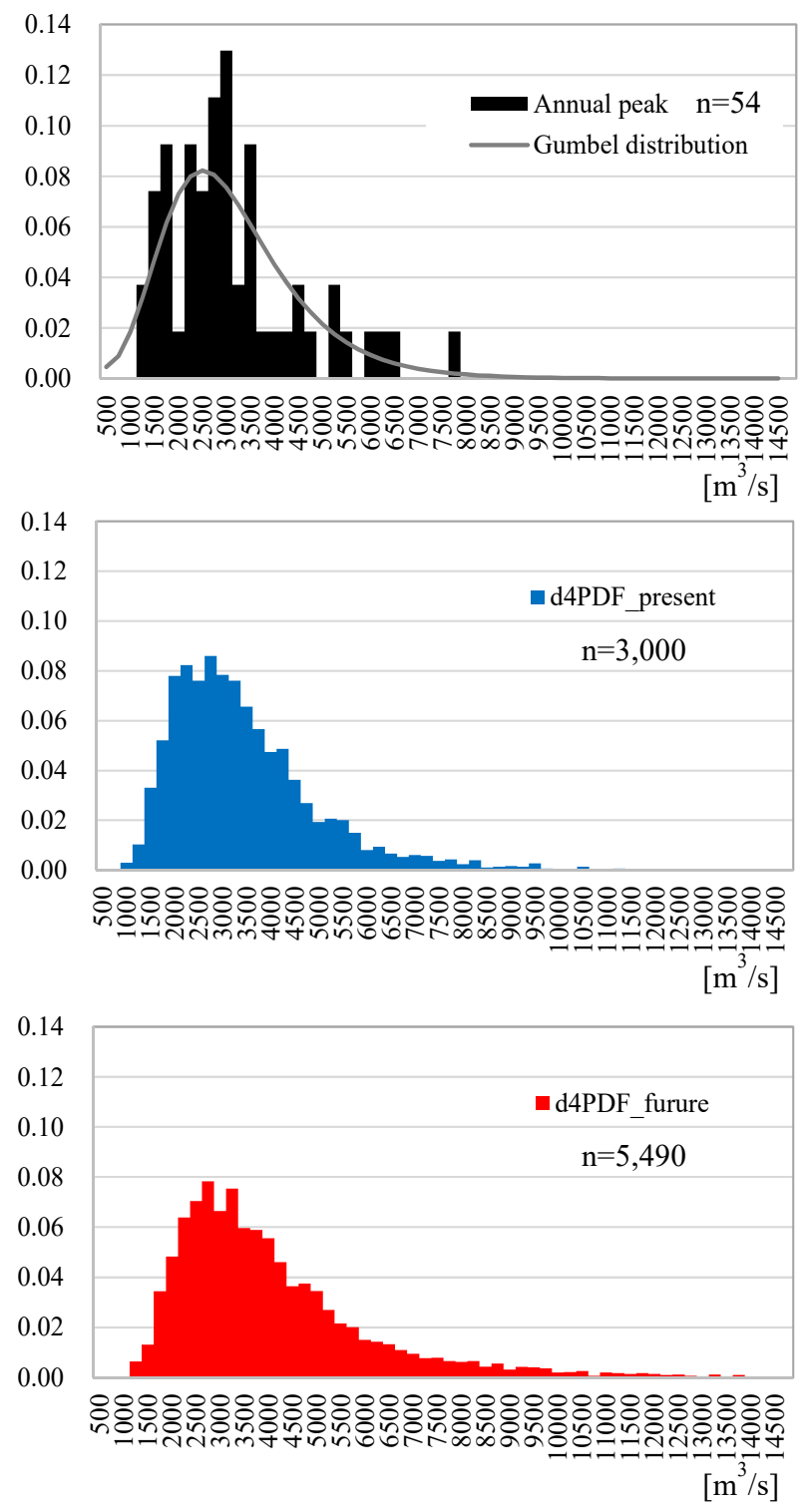

Fig.5 The frequency distribution of the observed annual maximum discharge in the Chusetsu watergauge station and the peak flood discharge in the runoff analysis results of the AMP events extracted from d4PDF.

historical experiment was $3,320 \mathrm{~m}^{3} / \mathrm{s}$. The average value of calculated result was about $10 \%$ larger than the average of the observed values.

We tried to make bias corrections using two simple methods and compared the results. [Method 1] minimizes the error to the cumulative distribution of observations. [Method 2] creates a Gumbel distribution corresponding to the observed value and minimizes the error for the top $10 \%$ of the Gumbell distribution. As a result of [Method 1], the correction coefficient $C=0.92\left(\mathrm{RMSE}=176.8 \mathrm{~m}^{3} / \mathrm{s}\right)$. As a result of [Method 2], the correction coefficient $C$ $=0.88\left(\mathrm{RMSE}=169.1 \mathrm{~m}^{3} / \mathrm{s}\right)$. At this time, the constant of the Gumbel distribution was $(a, c)=$ (1115.2, 2379.8). 

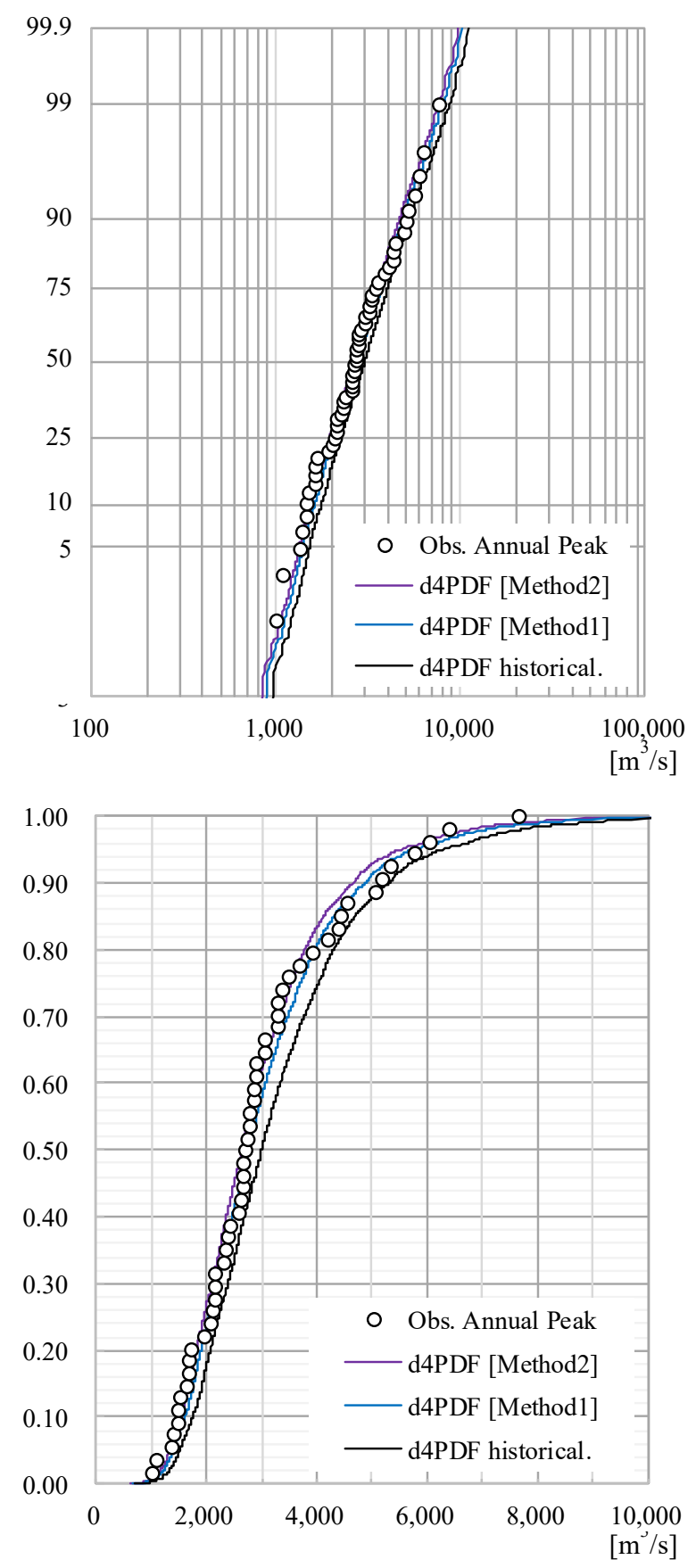

Fig.6 The observed annual peak discharge values, the distribution of the calculation results, and the distribution corrected by [Method 1] and [Method 2]. (Top: Log normal probability display, Bottom: Cumulative distribution function display).

Fig.6 shows the observed values, the distribution of the calculation results, and the distribution corrected by [Method 1] and [Method 2]. As shown in Fig.6, there is no significant difference between the results of Method 1 and [Method 2]. Although the correction result by [Method 2] is corrected for the Gumbel distribution, [Method 1] fits the distribution of observations better. Therefore, we selected [Method 1] in this study.

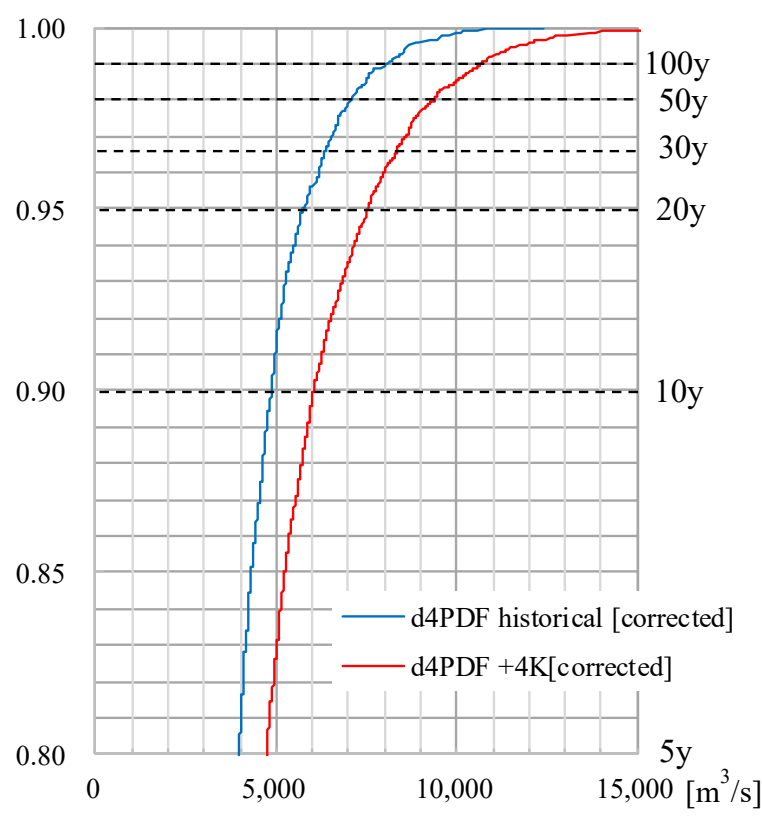

Fig.7 Evaluation of T-year possible flood discharge from corrected cumulative distribution of peak flood discharge.

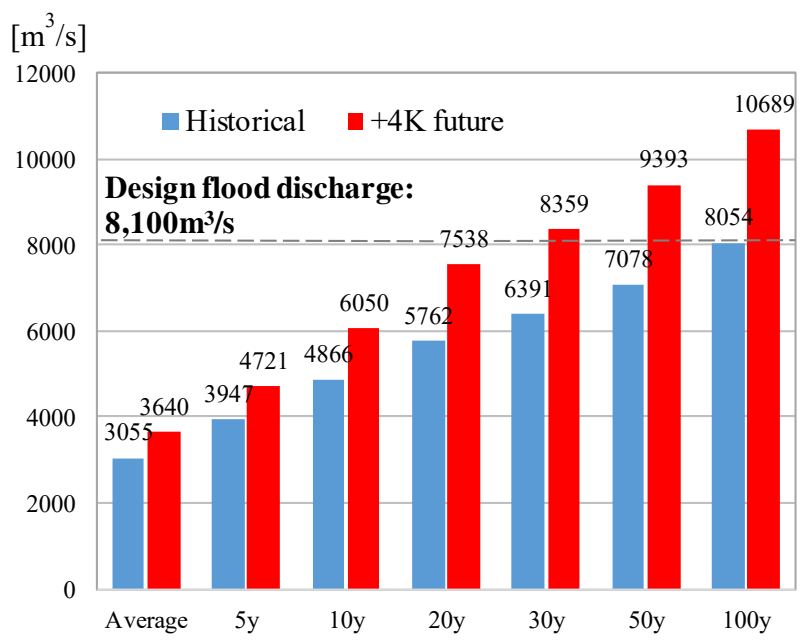

Fig.8 Evaluation result of T-year possible flood discharge at the Chusetsu watergauge station in the Nagara River.

(4) Evaluation of T-year possible flood discharge

Fig.7 shows a part of the cumulative distribution corrected by multiplying the flood peak discharge analysis results using d4PDF historical experiment and $+4 \mathrm{~K}$ experiment by the correction coefficient $C=0.92$. The vertical axis of the figure shows nonexcess probabilities of 0.80 to 1.00 , and the top $20 \%$ of the corrected calculation results are displayed in a cumulative distribution. The distribution is very smooth and the flood peak discharge with T-year excess probability can be calculated directly. As an example, for a flood flow with a probability of 100 years, the flow discharge $x$ corresponding to the non-excess probability $\mathbf{F}(x)=$ 0.99 is obtained from the cumulative distribution. In other words, by extracting the value correspond- 
ing to the top $1 \%$ of the cumulative distribution, the 100 -year probability flow rate $x$ can be extracted. Fig.8 shows the T-year possible flood discharge calculated based on the above method.

As a result of the evaluation, the peak flood flow in Chusetsu in the Nagara River was expected to increase by about $33 \%$ at the maximum when the average temperature increased by $4 \mathrm{~K}$ from before the Industrial Revolution. In addition, the probability of design flood discharge $8,100 \mathrm{~m}^{3} / \mathrm{s}$ occurring is now once every 100 years or more, but if the temperature rises by $4 \mathrm{~K}$, it is estimated that the probability of occurrence increases to once every 30 years.

\section{DISCUSSION}

\section{(1) Effects of a combination of climate model and runoff analysis model on evaluation re- sults}

As shown in Fig.6, the calculation results of the peak flood discharge using d4PDF NHRCM historical experiment well reproduced the frequency distribution of annual maximum flood discharge observed in the Nagara River, although tending to be overestimated. Therefore, a practical flood frequency analysis has become possible by multiplying the analysis result by the simple correction factor. However, the Nagara River basin is generally covered by nine grids in the d4PDF NHRCM used in this study. The reason why the analysis result of the coarse spatial resolution climate model gives the flood peak discharge frequency distribution well is discussed.

In the $20 \mathrm{~km}$ grid model, the elevation of the grid was given by averaging the elevation of the actual terrain within the grid. Therefore, mountainous landforms were represented as averaged flat topography, and this climate model did not represent orographic precipitations.

Kojima et al.$^{8)}$ compared the rainfall observed on the ground near Gifu with the rainfall of d4PDF NHRCM historical experiment based on extreme value statistics, and d4PDF tended to underestimate the maximum rainfall of 1 hour per year and overestimate the rainfall of 24 hours per year. This was particularly noticeable in mountainous areas such as Takayama city, which is located in the northern area of Gifu prefecture. This explains why the peak flood discharge in the Nagara River basin, where most of the basin is mountainous, was overestimated. Due to the coarse spatial resolution of the climate model, it was difficult to express local shortterm rainfall, orographic precipitation, etc., and characteristically, rain clouds tended to advance to the inland. The following reasons can be considered why the flood runoff analysis results using d4PDF NHRCM agreed well with the observed flood discharge in spite of these negative features of the climate model.

The first was the characteristics of the meteorological field that caused AMP events in the Nagara River basin. In this study, the AMP events were extracted with the areal-averaged precipitation in the Nagara River basin. The main causes of rainfall in the entire Nagara River basin are rainfall due to the seasonal rain front, rainfall involving typhoons on the front, and rainfall due to typhoons alone. These are all relatively large-scale meteorological phenomena, and even with a spatial resolution of $20 \mathrm{~km}$, it was inferred that the rainfall and hyetographs that fell throughout the basin were expressed to the extent that they enveloped actual phenomena.

The second is the characteristics of the runoff analysis model used in this study. The model in this study is the storage function method commonly used in river planning, and this model divides the watershed into larger units as compared to the distributed runoff analysis model. In the Nagara River basin model, the average area of 27 small watershed models was as wide as $63 \mathrm{~km}^{2}$. In addition, the model parameters for each small watershed were optimized for the rainfall hyetograph obtained by spatially interpolating the values of the ground rain gauge stations with the Thiessen method. In other words, the spatial distribution of precipitation input to this model was originally coarse. Furthermore, since the storage function behaved as a buffer against fluctuations in the rainfall hyetograph, the response of the model to short-term fluctuations in the rainfall hyetograph was inherently dull. As a result of the combination of these two factors, the calculation results of flood discharge using d4PDF were considered to be in good agreement with the observed values.

\section{(2) Versatility and applicability of this method}

The package of methods tested in this study was designed to make it easier for river managers to understand the results of flood frequency analysis, by using methods and observational materials that river managers have used for river planning, and by using as simple a method as possible. The climate change impact assessment using the runoff analysis model gained trust by the following methods, to reproduce the model used for river planning as it is, to use the annual maximum flow observation value at the watergauge station directly for the model verification, and to show the results of the historical and global warming foreseen future by using the 
large ensemble climate model, etc. This method can relatively show the influence of global warming on the frequency of floods using the expressions used in river planning. The materials necessary for the implementation of this method can be obtained in other river basins with the cooperation of river managers, and this method is considered to have versatility that can be widely applied.

The method presented in this study has the following problems: First is the problem posed by the regional characteristics of rainfall-runoff characteristics. Because the rainfall phenomenon expressed by the climate model does not include all the rainfall events, the climate model may not be able to express the rain phenomenon that causes flooding in the target area. In this study, when determining the correction coefficient of the calculation result, the coefficient determined by focusing only on the historical experiment was also used for the calculation result of the $+4 \mathrm{~K}$ experiment. These issues may need to be verified and improved.

\section{SUMMARY}

The annual maximum precipitation events in the Nagara River basin were extracted from the historical experiments and $+4 \mathrm{~K}$ future experiments of d4PDF NHRCM, and flood runoff analysis was performed using a storage function method model. The frequency distribution of the calculation result of the peak flood discharge was overestimated by about $10 \%$ from the frequency distribution of the observed values. As a result of introducing a simple correction coefficient to the calculation result, the distribution of the annual maximum discharge was well reproduced. Using d4PDF historical experiment and $+4 \mathrm{~K}$ future experiment, we propose a method to evaluate the flood frequency in the target basin relatively and quantitatively. This method has versatility that can be applied to other river basins and provides a smooth risk communication with river managers and citizens.

ACKNOWLEDGMENT: This research was supported by the Social Implementation Program on
Climate Change Adaptation Technology (SI-CAT) of the Ministry of Education, Culture, Sports, Science and Technology (MEXT), Japan. This study used d4PDF produced with the Earth Simulator jointly by science programs (SOUSEI, TOUGOU, SI-CAT, DIAS) of the MEXT, Japan. In addition, we received various materials related to the Nagara River from Gifu Prefecture officials who are river managers in the middle and upper reaches of the Nagara River.

\section{REFERENCES}

1) Hawkins, E. and Sutton, R.: The potential to narrow uncertainty in regional climate predictions, Bulletin of the American Meteorological Society, Vol.90 (8), pp. 10951107, 2009.

2) Min, S. K., Zhang, X., Zwiers, F. W. and Hegerl, G. C.: Human contribution to more intense precipitation extremes, Nature, Vol. 470 (7334), pp. 378-381, 2011.

3) Sasaki, H., Murata, A., Kawase, H., Hanafusa, H., Nosaka, M., Oh'izumi, M., Mizuta, R., Aoyagi, T., Shido, F. and Ishihara, K.: Projection of Future Climate Change around Japan by using MRI Non-hydrostatic Regional Climate Model, Technical Reports of the Meteorological Research Institute, No. 73, 104 pp., 2015.

4) Database for Policy Decision making for Future climate change (d4PDF) (http://www.miroc-gcm.jp/ pub/d4PDF/)

5) Kawasaki, A., Yamamoto, A., Koudelova, P., Acierto, R. A., Nemoto, T., Kitsuregawa, M. and Koike, T.: Data Integration and Analysis System (DIAS) Contributing to Climate Change Analysis and Disaster Risk Reduction, Data Science Journal, Vol. 16 (41), pp. 1-17, 2017.

6) Tanaka, S.: Frequency Analysis of Extreme Precipitation in the Tone River Basin using "d4PDF" [In Japanese with English synopsis], DPRI Annuals, Vol. 60B, pp. 757-764, 2017.

7) Water and Disaster Management Bureau of the Ministry of Land, Infrastructure Transport and Tourism, Japan: Document 5 Kiso River Basin Development Basic Policy Document on Basic High Water (Draft) [In Japanese], 2335 ,

2007.(https://www.mlit.go.jp/river/shinngikai_blog/shasei shin/kasenbunkakai/shouiinkai/kihonhoushin/070731/070 731-siryo.html)

8) Kojima, T., Maruya, Y. and Harada, M.: Proposal of the Bias Correction Values of Probability Rainfall by $20-\mathrm{km}$ d4PDF for Future Land Slide Risk Assessment, Journal of Japan Society of Civil Engineers, Ser.B1 (Hydraulic Engineering), Vol. 74, No. 5, pp. I_133-I_138, $2018 .$.

(Received October 1, 2019)

(Accepted January 8, 2020) 